\title{
Mangrove leaves with outstanding content of free amino acids especially GABA, makes them candidates for functional food
}

\author{
1,3,"Hinokidani, K., ${ }^{2}$ Koyama, S., ${ }^{3}$ Irie, M. and ${ }^{3}$ Nakanishi, Y. \\ ${ }^{1}$ Faculty of Regional Environment Science, Department of Bioproduction and Environment Engineering, \\ Tokyo University of Agriculture, 1-1-1 Sakuragaoka, Setagaya, Tokyo 156-8502, Japan \\ ${ }^{2}$ Graduate School of Agriculture, Department of Agricultural Chemistry, Tokyo University of Agriculture, 1- \\ 1-1 Sakuragaoka, Setagaya, Tokyo 156-8502, Japan \\ ${ }^{3}$ Faculty of International Agriculture and Food Studies, Department of International Agricultural \\ Development, Tokyo University of Agriculture, 1-1-1 Sakuragaoka, Setagaya, Tokyo 156-8502, Japan
}

\section{Article history: \\ Received: 22 April 2020 \\ Received in revised form: 11 \\ May 2020 \\ Accepted: 15 May 2020 \\ Available Online: 12 June 2020}

Keywords:

Mangroves,

Amino acids,

Bioactive compound,

LC-MS analysis,

GABA

DOI:

https://doi.org/10.26656/fr.2017.4(5).185

\begin{abstract}
Herbal remedies by using mangrove plants have been recognized in several countries, and the plant materials are often consumed as a tea, which are infusions of dried plant parts steeped in boiling water. These infusions from mangrove plants are believed to be effective agents for treating and/or prevent infections, ailments, and diseases, and some mangrove plants have attracted attention as functional food resources in recent years. To reveal the beneficial properties of mangrove plants, clarification of the chemical ingredient and its characteristics of mangrove plants is required. This study focused on amino acids, which were functional ingredients (i.e., bioactive compounds) because amino acids are expected to function as 'functional ingredients' in addition to conventional 'nutrients' in recent years. To demonstrate the further possibilities of mangrove tea, we firstly evaluated the content of total amino acids in the leaf of several dominant mangrove species with commercial teas as references. Next, we clarified the composition of amino acids by using LC-MS analysis. As the results, free amino acid content (FAC) in leaf sample of Rhizophora stylosa, Bruguira gymnorrhiza, Kandelia obovata, Avicennia marina, Sonneratia alba, and Lumnitzera racemosa was 747, 1056, 946, 829, 623, and $896 \mathrm{mg} / 100 \mathrm{~g} \mathrm{DW}$, respectively. The FAC in all mangrove leaf samples were higher than those in green tea of low price, black tea, oolong tea, barley tea, and mate tea. Moreover, it was found that GABA accounts for over $10 \%$ of the total amino acid in the mangrove leaf samples. Especially in mature leaves of $K$. obovata, the ratio was very high levels $35 \%$. In the case of $K$. obovata, the contents were higher than GABA tea. Based on this, we concluded that several mangrove plants, especially $K$. obovata has the potential of a functional food which is GABA-rich.
\end{abstract}

\section{Introduction}

Mangroves are plant communities of the intertidal coastal zone in the tropics and subtropics and provide many goods and services to people who live in coastal regions (Spalding et al., 2010). Mangrove Educational Book Series No. 3 (Baba et al., 2013) have summarized useful products from mangrove and other coastal plants. In this book, uses of mangroves to tea materials for herbal remedies were introduced. For example, herbal remedies by using several mangrove plants have been used to treat infections, ailments, diseases, and more, and they are often consumed as teas, which are infusions of dried plant parts steeped in boiling water (Baba et al.,
2013). For example, in Thailand, the leaves of Acanthus ebracteatus and Pluchea indica are often consumed as herbal teas. According to Cheeptham and Towers (2002), A. ebracteatus can relieve body aches, allergies, colds, low immunity, insomnia, infected wounds, and fever, and $P$. indica can be effective for diabetes and hemorrhoids. In Mexico, people who live in the fishing village consume herbal tea made from the leaves of Avicennia germinans (Hernández-Cornejo et al., 2005), and it is believed to be effective in treating gastric disorders. In India, Kathiresan (1990) has investigated whether the leaves of Bruguiera cylindrica, Ceriops decandra, Rhizophora apiculata, Rhizophora lamarckii, and Rhizophora mucronata can be used as an alternative 
tea material. As a result, it was shown that theaflavin, tea polyphenols, was contained in fermented the mangrove leaves, and the teas are no toxic effects in experimental animals. Regarding the comparison study of mangrove leaves and teas, there are few studies so far. However, recently Chan et al. (2017) have conducted experiments on antioxidant, anti-tyrosinase, and anti-quorum sensing activities by using four mangrove species ( $R$. apiculata, Rhizophora stylosa, Sonneratia alba, and Avicennia rumphiana) and green tea. According to this study, it was indicated that the antioxidant activity of extracts from mangrove plants are inferior to green teas. However, the extracts from two mangrove species $(R$. apicurata and $S$. alba) were present strong antityrosinase activity than green tea. In this way, revealing those functional properties of mangrove plants would promote the understanding of mangroves as useful natural food resources.

On the other hand, common commercial teas (e.g., green tea) contains various components, such as polyphenol, caffeine, amino acids, vitamins, minerals, and more, and its characteristics and the contents determine the quality and price of the beverage. Among them, this study focuses on amino acids, which are functional ingredients (i.e., bioactive compounds). Recently, as researches on the individual physiological functions of amino acids progress, they are expected to function as 'functional ingredients' in addition to conventional 'nutrients'. For example, GABA $(\gamma$ aminobutyric acid) has especially been attracting attention as a functional ingredient with its anti-stress effect, and it is the spotlight. However, the knowledge of the amino acids, especially functional amino acids, in mangrove plants is limited.

Therefore, to demonstrate the further possibilities of mangrove tea, we firstly examined the content of total amino acids in the leaf of several dominant mangrove species, which is growing in the Ryukyu archipelago, Okinawa, Japan. Next, we clarified the composition of amino acids by using LC-MS analysis, and a remarkable component in the mangrove leaves.

\section{Materials and methods}

\subsection{Colorimetric assay for free amino acid}

For an experiment, leaf samples of 6 species of mangrove (Rhizophora stylosa, Bruguiera gymnorrizha, Kandelia obovata, Sonneratia alba, Avicennia marina, and Lumnitzera racemosa) were collected from Iriomote Is. (Lat. $24^{\circ} 17^{\prime} \mathrm{N}$, Long. $123^{\circ} 51^{\prime} \mathrm{E}$ ), Ishigaki Is. (Lat. $24^{\circ}$ $20^{\prime} \mathrm{N}$, Long. $124^{\circ} 09^{\prime} \mathrm{E}$ ), Miyako Is (Lat. $24^{\circ} 46^{\prime} \mathrm{N}$, Long. $125^{\circ} 19^{\prime} \mathrm{E}$ ), and Okinawa Is. (Lat. $24^{\circ} 12^{\prime} \mathrm{N}$, Long. $127^{\circ}$ $40^{\prime} \mathrm{E}$ ), Japan in 2015-2016, and 9 kinds of commercial tea (5 kinds of green tea (low price Sencha: brand A; middle price Sencha: brand B, C, D; high price Gyokuro: brand E), black tea, oolong tea, barley tea, and mate tea) were prepared as the control.

The extraction of the amino acids from leaf samples followed the previous study on the analysis of tea (Ikegaya et al., 1990). The amount of $0.1 \mathrm{~g}$ of each dried powder sample was placed in a $100 \mathrm{~mL}$ glass conical flask, and $80 \mathrm{~mL}$ of boiled water was added to the flask. The flask was placed into thermobath, keeping $80^{\circ} \mathrm{C}$ for 30 mins. After cooling at room temperature $\left(20 \pm 5^{\circ} \mathrm{C}\right)$, the contents were filtered (No.2, ADVANTEC) and transferred to a volumetric flask and diluted to a final volume of $100 \mathrm{~mL}$. The extracts were stored in a fridge at $4^{\circ} \mathrm{C}$ until analysis.

The total free amino acid in the leaf water extract was measured by using the Ninhidorin colorimetric method (Ikegaya et al., 1990). An amount of $300 \mathrm{mg}$ of polyvinylpolypyrrolidone (Sigma-Aldrich) was added to $100 \mathrm{~mL}$ of the leaf-water extract, and the mixture was shaken, allowed to stand for 30 mins, and filtered again to obtain a sample solution. An aliquot $(1 \mathrm{~mL})$ of the solution diluted 2-fold was taken in a test tube, $0.5 \mathrm{~mL}$ of Ninhydrin solution (5 $\mathrm{g}$ of ninhydrin [2,2Dihydroxyindane-1,3-dione] dissolved in $250 \mathrm{~mL}$ of 2methoxyethanol and mixed with $\mathrm{pH} 5.2$ citrate buffer solution at ratio 1: $1(\mathrm{v} / \mathrm{v})[0.4 \mathrm{M}$ citric acid adjusted to $\mathrm{pH} 5.2$ with $2 \mathrm{~N}$ aqueous sodium hydroxide]) and $0.5 \mathrm{~mL}$ of tin (II) chloride solution (50 g of tin (II) chloride was dissolved in $25 \mathrm{~mL}$ of $\mathrm{pH} 5.2$ citrate buffer solution) were added to the tube, vortexed, and heated in a thermobath $\left(80^{\circ} \mathrm{C}\right)$ for 30 mins.

After returning the test tube to room temperature by cooling in tap water, $5 \mathrm{~mL}$ of aqueous 2-propanol $(50 \%$, $\mathrm{v} / \mathrm{v}$ ) was added to the tube and mixed with a vortex mixer. After that, the absorbance in the solution was determined at a wavelength of $570 \mathrm{~nm}$ using a spectrophotometer. The measurement was carried out using distilled water as a blank, and L-glutamic acid (for Amino Acid Analysis, FUJIFILM Wako Pure Chemical Co., Japan) as a standard reagent. From the calibration curve, the free amino acid content was determined and expressed to mg per g dry weight. All the extraction procedures and measurements were performed in triplicate.

\subsection{Quantification of amino acids by LC-MS}

For experiment samples, three mangrove leaf samples, R. stylosa, B. gymnorrhiza, and K. obovata, were collected from a mangrove forest in Shimajiri estuary, Miyako Island, Japan, in March 2017. When collecting the leaf samples, fully matured leaves and 
young leaves in each of the species were collected from at least five different trees, which are of the same level height, at the sampling site. After collection, leaf samples were dried by freeze-drying machine and ground into fine powder with a mill (WB-1, OSAKA CHEMICAL). As the reference sample, green tea leaf (brand F; high price green tea) was also prepared as well.

Amino acids in the leaf samples were extracted in the same manner as colorimetric assay for free amino acid. In this study, 22 amino acids (Phenylalanine, Tryptophan, Leucine, Isoleucine, Methionine, Proline, Tyrosine, Valine, Theanine, Alanine, Threonine, Glutamic acid, Aspartic acid, Glycine, Glutamine, Serine, Asparagine, Cystine, GABA, Lysine, Arginine, Histidine) were investigated. Amino acids in the mangrove leaves were identified and quantified by LC-Q -TOF (Agilent 1260 Infinity LC and Agilent 6530 QTOF LC-MS system, Agilent Technologies, U.S.A). Chromatographic separation was achieved on an Intrada Amino Acid column $(100 \times 3 \mathrm{~mm}$ i.d., $2.7 \mu \mathrm{m}$, Imtakt Corporation, Japan). Chromatographic conditions were

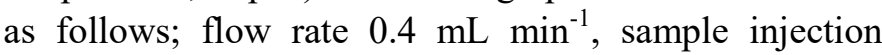
volume of $1 \mu \mathrm{L}$, and mobile phase A: acetonitrile /formic acid $=100 / 0.1$, and mobile phase B: $100 \mathrm{mM}$ ammonium formate. The following gradient program was used; $14 \%$ $\mathrm{B}$ in 3 mins, from $14 \%$ to $100 \% \mathrm{~B}$ in 9 mins. The column oven was set at $35^{\circ} \mathrm{C}$. Q-TOF conditions were as follows; ionization method: electrospray ionization in positive, drying gas: $6 \mathrm{~L} \mathrm{~min}^{-1}$ at $300^{\circ} \mathrm{C}$, fragmenter: 80 $\mathrm{V}$, skimmer: $50 \mathrm{~V}$, sheath gas: $12 \mathrm{~L} \mathrm{~min}^{-1}$ at $400^{\circ} \mathrm{C}$. For the standard of 22 amino acids, amino acids mixture standard solution type $\mathrm{H}$ was used (FUJIFILM Wako Pure Chemical Co., Japan).

\section{Results}

\subsection{Colorimetric assay for free amino acid}

Commercial green teas, which are known to be high amino acid content, were used for a reference in this experiment. In addition to the green tea, 4 types of common teas (black tea, oolong tea, barley tea, and mate tea) were also used for the experiments. Free amino acid content (FAC) of the mangrove leaf or tea extracts were determined by the Nynhidrin colorimetric assay. FAC in mangrove leaf samples compared with those in commercial teas are shown in Figure 1. FAC in leaf sample of Rhizophora stylosa, Bruguira gymnorrhiza, Kandelia obovata, Avicennia marina, Sonneratia alba, and Lumnitzera racmosa were 747, 1056, 946, 829, 623, and $896 \mathrm{mg} / 100 \mathrm{~g} \mathrm{DW}$, respectively. FAC in all mangrove leaf samples was higher than those in green tea of low price $(420 \mathrm{mg} / 100 \mathrm{~g} \mathrm{DW})$, black tea $(570$ $\mathrm{mg} / 100 \mathrm{~g} \mathrm{DW})$, oolong tea (236 mg/100 g DW), barley tea $(254 \mathrm{mg} / 100 \mathrm{~g} \mathrm{DW})$, and mate tea $(137 \mathrm{mg} / 100 \mathrm{~g}$
DW). Regarding B. gymnorrhiza which was the highest free amino acid content, the FAC was relatively the same levels with green tea of middle price, ranged from 1140 to $1207 \mathrm{mg} / 100 \mathrm{~g} \mathrm{DW}$.

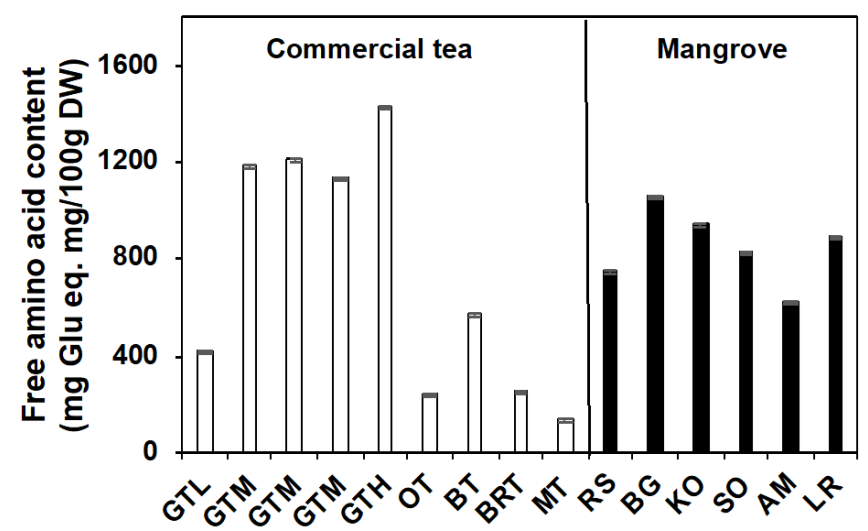

GTL: green tea of low price (36US $\$ / \mathrm{kg}$ ); GTM: green tea of middle price (80US $\$ / \mathrm{kg}$ ); GTH: green tea of high price (154US \$/kg); OT: oolong tea; BT: black tea; BRT: barley tea; MT: mate tea.

RS: Rhizophora stylosa; BG: Bruguiera gymnorrhiza; KO: Kandelia obovata; SO Sonneratia alba; AM: Avicennia marina; LR: Lumnitzera racemosa.

Figure 1. Free amino acids contents in mangrove leaf samples compared with those in commercial teas.

\subsection{Quantification of amino acids by LC-MS}

A total of 22 amino acids were detected from mangrove leaf samples, and those contents comparison with reference green tea are shown in Figure 2. Amounts of phenylalanine, tryptophan, leucine, isoleusine, prolin, tyrosine, valine, theanine, glutamic acid, aspartic acid, glutamine, asparagine, lysine, and histidine were higher in reference green tea than those in leaf sample of Rhizophora stylosa, Bruguira gymnorrhiza, Kandelia obovata, Avicennia marina, Sonneratia alba, and Lumnitzera racemosa. Amounts of methionine and glycine were higher in the mangrove leaves than those in the green tea. The amounts of alanine in young leaves of B. gymnorrhiza and $K$. obovata were 3 hold higher than the mature leaves, and those of the young leaves were higher than those in the green tea. Regarding the young leaves of $K$. obovata, amounts of threonine and serine were 2-3 times higher than those of the green tea. Amounts of cystine in $R$. stylosa leaves (both of young and mature leaves) were 2-3 times higher than those of the green tea. Amounts of GABA ( $\gamma$ - aminobutyric acid) in $K$. obovata leaves (both of young and mature leaves) were 4 times higher than those of the green tea.

The ratio of each amino acid to total amino acid was shown in Table 1 to compare the composition of amino acids in each mangrove leaf samples and reference green tea. It was found that glutamic acid (30\%), Theanine (17\%), and aspartic acid (13\%) accounts for $60 \%$ of total amino acid in green tea. On the other hand, it was found that GABA accounts for over $10 \%$ of the total amino acid in the mangrove leaf samples. Especially in mature 

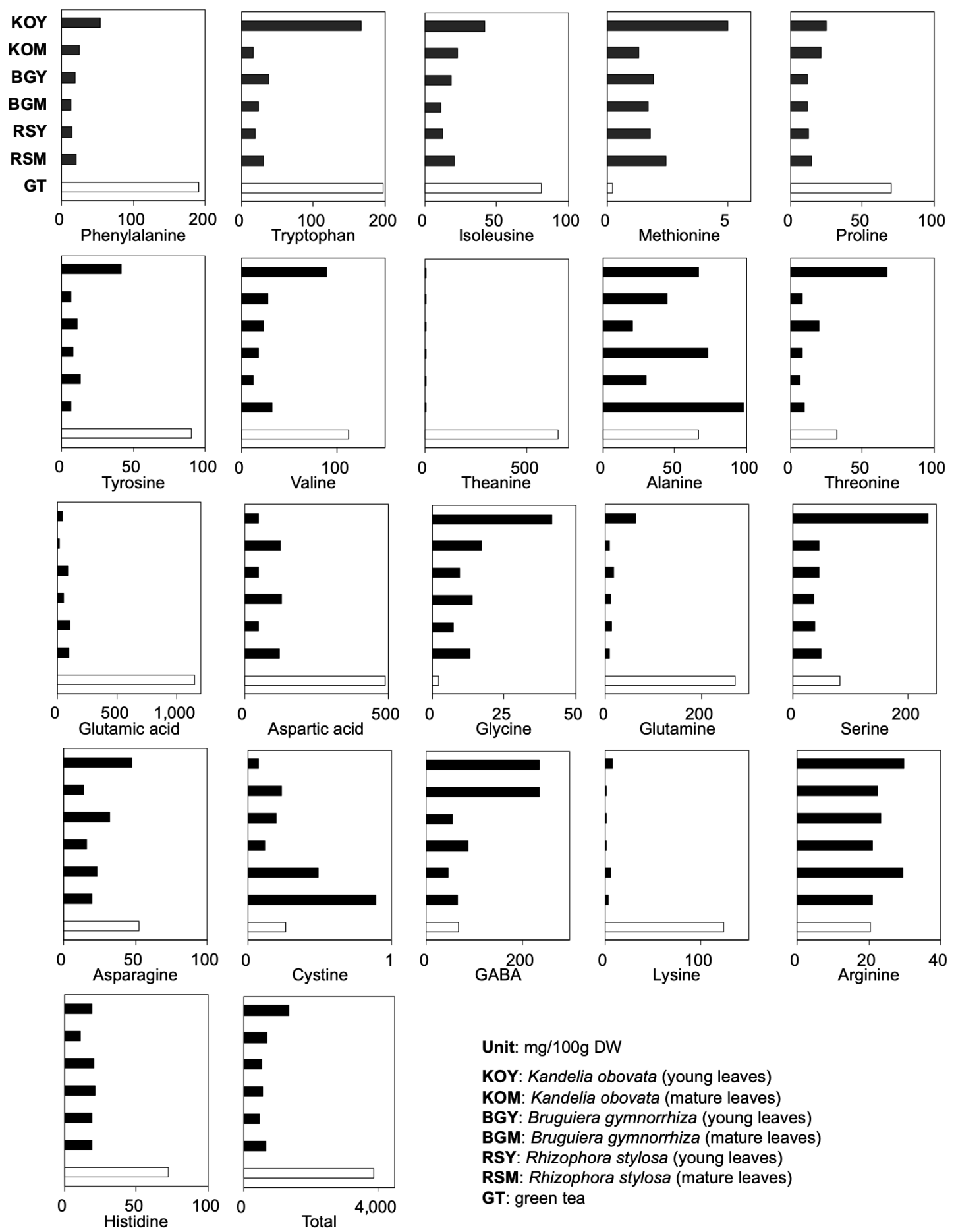

\begin{abstract}
Unit: $\mathrm{mg} / 100 \mathrm{~g}$ DW
KOY: Kandelia obovata (young leaves)

KOM: Kandelia obovata (mature leaves)

BGY: Bruguiera gymnorrhiza (young leaves)

BGM: Bruguiera gymnorrhiza (mature leaves)

RSY: Rhizophora stylosa (young leaves)

RSM: Rhizophora stylosa (mature leaves)

GT: green tea
\end{abstract}

Figure 2. Twenty-two amino acids detected from mangrove leaves and comparison of those with reference green tea.

Table 1. The ratio of each amino acid to the total amino acid.

\begin{tabular}{|c|c|c|c|c|c|c|c|c|c|c|c|c|c|c|c|c|c|c|c|c|c|c|}
\hline \multirow[b]{2}{*}{ Sample } & \multicolumn{22}{|c|}{ The ratio of each amino acid to total amino acids (\%) } \\
\hline & $\vec{\sigma}$ & $\exists$ & 5 & $\overline{0}$ & $\frac{3}{3}$ & $\overrightarrow{0}$ & 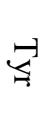 & 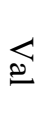 & $\vec{\nabla}$ & $\underset{D}{D}$ & $\stackrel{ }{ }$ & $\cong$ & $\frac{D}{8}$ & $\stackrel{Q}{<}$ & $\stackrel{Q}{E}$ & $\stackrel{\mathscr{Q}}{\oplus}$ & $\begin{array}{l}\vec{D} \\
B\end{array}$ & $\overbrace{\infty}$ & $\stackrel{D}{D}$ & $\underset{\infty}{\stackrel{s}{*}}$ & $\underset{00}{\gtrless}$ & $\stackrel{\vec{p}}{\vec{s}}$ \\
\hline Green tea & 5 & 5 & 2 & 1 & 0 & 2 & 2 & 3 & 17 & 2 & 1 & 30 & 13 & 0 & 7 & 2 & 1 & 0 & 2 & 3 & 1 & 2 \\
\hline RS* mature & 3 & 5 & 3 & 3 & 0 & 2 & 1 & 5 & 0 & 15 & 1 & 15 & 18 & 2 & 1 & 7 & 3 & 0 & 10 & 0 & 3 & 3 \\
\hline RS young & 3 & 4 & 3 & 2 & 0 & 3 & 3 & 2 & 0 & 6 & 1 & 22 & 11 & 2 & 3 & 8 & 5 & 0 & 10 & 1 & 6 & 4 \\
\hline $\mathrm{BG}^{* *}$ mature & 2 & 4 & 2 & 1 & 0 & 2 & 1 & 3 & 0 & 13 & 1 & 9 & 23 & 2 & 2 & 6 & 3 & 0 & 16 & 0 & 4 & 4 \\
\hline BG young & 4 & 7 & 4 & 2 & 0 & 2 & 2 & 4 & 1 & 4 & 4 & 17 & 9 & 2 & 3 & 9 & 6 & 0 & 10 & 0 & 4 & 4 \\
\hline $\mathrm{KO}^{* * *}$ mature & 4 & 2 & 3 & 1 & 0 & 3 & 1 & 4 & 0 & 7 & 1 & 3 & 18 & 3 & 1 & 7 & 2 & 0 & 35 & 0 & 3 & 2 \\
\hline $\mathrm{KO}$ young & 4 & 12 & 3 & 2 & 0 & 2 & 3 & 7 & 0 & 5 & 5 & 3 & 4 & 3 & 5 & 17 & 4 & 0 & 18 & 1 & 2 & 1 \\
\hline
\end{tabular}

*Rhizophora stylosa **Bruguiera gymnorrhiza ***Kandelia obovata 
leaves of $K$. obovata, the ratio was a very high level of $35 \%$.

\section{Discussion}

There are few reports on free amino acid content in mangrove plants except for Popp et al. (1984), which surveyed for the amino acids in Australian mangroves and the knowledge are limited. In those situations, this study provides new information on the amino acid comparison with green tea. Based on this comparison study for amino acid, we discuss potentials from as alternative tea materials of mangrove leaves.

Among beverages of plant origin, especially green tea contains highly amino acids, and the content greatly higher-grade green teas contain greater amounts of total amino acids (theanine, and other individual amino acids) than the lower-grade green teas (Goto et al., 1996). Similarly, the amounts of free amino acid determined by a colorimetric assay in this study were highest in the high price and the middle price of green teas than those in a low price of green tea. Then, free amino acid contents (FAC) in all mangrove leaf samples were inferior to the higher-grade tea (Figure 1). However, FAC in the mangrove leaves was higher than the low price of green and a mate tea. Therefore, when using mangrove leaves for tea materials, the water-extract can be expected to intake a relatively high amount of amino acids compared with common teas.

For the next, the amino acid composition in mangrove leaf samples was examined by LC-MS analysis. As a result, GABA, aspartic acid, and glutamic acid were the principal amino acids in Rhizophora stylosa, Bruguiera gymnorrhiza, and Kandelia obovata (Figure 2 and Table 1). As the opposite of the mangrove leaves, GABA content in the green tea was lower-level, and the major components in the tea were theanine, glutamic acid, and aspartic acid. According to these results, it was indicated that GABA is the most characteristic amino acid in mangrove leaves.

It has shown that high levels of GABA accumulate rapidly in plant tissues exposed to a variety of different stresses (Kinnersley and Turano, 2000). For example, the situation has been reported in drought-stressed cotton (Hanower and Brzozowska, 1975), heat-stressed cowpea cells (Mayer et al., 1990), and soybeans subjected to cold stress (Wallace et al., 1984). In a more recent study, it was suggested that GABA mitigate water stress by acting as an osmolyte (Shelp et al., 1999). Mangrove plants grow in high salinity conditions and hypoxia due to frequent floods by tidal currents. Therefore, these habitat influences the quality of the tea. It is reported that the tea, as well as a black tea, an oolong tea, a barley tea,

characteristics can be one of the reasons why the mangrove plants produce much GABA in leaf tissue. GABA content in the leaves of $R$. stylosa and $B$. gymnorrhiza were ranged between 46 to $88 \mathrm{mg} / 100 \mathrm{~g}$ DW, and those of $K$. obovata were over $200 \mathrm{mg} / 100 \mathrm{~g}$ DW in both mature and young leaves. The enormous difference of GABA content between two mangrove species (R. stylosa and B. gymnorrhiza) and K. obovata was seemed to be originated in the deference of physiological responses related to osmotic systems. Furthermore, the soil salinity and flooding level in their habitat may be related to the accumulation of GABA. Regarding these unclarified issues, it would be clearer by conducting for plant physiological experiments focused on the relationship between osmotic systems and GABA production. Progress in the future study is expected.

GABA has recently been attracting attention as a functional food ingredient with its anti-stress effect (Mori et al., 2007; Abdou et al., 2008). Besides

Table 2. GABA ( $\gamma$ - aminobutyric acid) content in (a) GABA natural foods and products which highly contained GABA and (b) the contents of mangrove leaves.

(a)

\begin{tabular}{lcl}
\hline $\begin{array}{c}\text { GABA-rich Functional } \\
\text { Foods }\end{array}$ & $\begin{array}{c}\text { Content } \\
(\mathrm{mg} / 100 \mathrm{~g} \\
\mathrm{DW})\end{array}$ & References \\
\hline Teas & & \\
\hline GABA tea & $>150$ & Zhao et al. $(2011)$ \\
& 181 & Wang et al. $(2006)$ \\
Pu-erh tea & 1.6 & Zhao et al. $(2011)$ \\
White tea & $13-20$ & Hou et al. $(2010)$ \\
Green tea & 46 & Zhao et al. $(2011)$ \\
& 18 & \\
Black tea & 17 & Wang et al. $(2006)$ \\
Oolong tea & 22 & Zhao et al. $(2011)$ \\
\hline
\end{tabular}
Cereals

\begin{tabular}{lcl} 
Brown rice & $1-10$ & Roohinejad et al. (2009) \\
Barley sprouts & 3 & Oh et al. (2003) \\
Bean sprouts & 3 & \\
Beans & 3 & \\
Corn & 2 & \\
Barley & 2 & \\
\hline Vegetables & & \\
\hline Spinach & 4 & Oh et al. (2003) \\
Potatoes & 2 & \\
Sweet potatoes & 1 & \\
Yams & 1 & \\
Kale & 1 & \\
Chestnut & 2 & \\
\hline Others & & \\
$\quad$ Roasted cocoa nibs & 52 & Stark et al. (2006) \\
Soya yogurt & 42 & Park and Oh (2007) \\
\hline
\end{tabular}


Table 2 (Cont.). GABA ( $\gamma$ - aminobutyric acid) content in (a) GABA natural foods and products which highly contained GABA and (b) the contents of mangrove leaves.

(b)

\begin{tabular}{cc}
\hline Mangroves & Content (mg/100 g DW) \\
\hline Rhizophora stylosa & \\
\hline Mature leaves & 65 \\
Young leaves & 46 \\
\hline Bruguiera gymnorrhiza & 88 \\
\hline Mature leaves & 54 \\
Young leaves & \\
\hline Kandelia obovata & 237 \\
\hline Mature leaves & 236 \\
Young leaves &
\end{tabular}

anti-stress effect, GABA is also reported that is effective for alleviating increases in blood pressure (Omori et al., 1987; Yasui et al., 2004; Shirai et al., 2011), mental symptoms in menopausal and presenile autonomic nervous disorders (Okuda et al., 2000), growth hormone secretion (Cavagnini et al., 1980), kidney function disorder (Lin et al., 2000; Kim et al., 2004), neutral fat increase (Ohtomo et al., 2010), and more. Therefore, GABA-rich foods are a high added value, and several GABA-rich foods are developing in a few decades (e.g., tea, chocolate, yogurt, and rice). GABA content in natural foods and products which highly contained GABA are shown in Table 2 with the contents of mangrove leaves. GABA content in $R$. stylosa and $B$. gymnorrhiza were mostly higher than those of the listed foods except for GABA tea, and in the case of $K$. obovata, the contents were higher than GABA tea. Based on this, we concluded that several mangrove plants, especially $K$. obovata have the potential of a functional food which is GABA-rich.

\section{Conflict of interest}

The authors declare no conflict of interest.

\section{Acknowledgments}

We thank the reviewers for very useful suggestions that helped us rework.

\section{References}

Abdou, A.M., Higashiguchi, S., Horie, K., Kim, M., Hatta, H. and Yokogoshi, H. (2006). Relaxation and immunity enhancement effects of $\gamma$-Aminobutyric acid (GABA) administration in humans. BioFactors, 26(3), 201-208. https://doi.org/10.1002/ biof.5520260305

Baba, S., Chan, H.T. and Aksornkoae, S. (2013). ISME
Mangrove Educational Book Series No.3 Useful Products from Mangrove and Other Coastal Plants. Okinawa, Japan: International Society for Mangrove Ecosystems.

Cavagnini, F., Benetti, G., Invitti, C., Ramella, G., Pinto, M., Lazza, M., Dubini, A., Marelli, A. and Müller, E.E. (1980). Effect of gamma-aminobutyric acid on growth hormone and prolactin secretion in man: influence of pimozide and domperidone. The Journal of Clinical Endocrinology and Metabolism, 51(4), 789-792. https://doi.org/10.1210/jcem-51-4-789

Chan, E.W.C., Ng, S. M., Sim, B.W.K., Tan, H.C. and Lo, Z.L. (2017). Antioxidant, anti-tyrosinase and anti -quorum sensing activities of four mangrove tree species vs. green tea. Journal of Applied Pharmaceutical Science, 7(7), 225-229. https:// doi.org/10.7324/JAPS.2017.70733

Cheeptham, N. and Towers, G.H. (2002). Light-mediated activities of some Thai medicinal plant teas. Fitoterapia, 73(7-8), 651-662. https:// doi.org/10.1016/S0367-326X(02)00224-1

Goto, T., Yoshida, Y., Amano, I. and Horie, H. (1996). Chemical composition of commercially available Japanese green tea. Foods and Food Ingredients Journal of Japan, 170, 46-52. [In Japanese].

Hanower, P. and Brzozowska, J. (1975). Influence d'un choc osmotique sur la composition des feuilles de cotonnier en acides amines libres. Phytochemistry, 14(8), 1691-1694. https://doi.org/10.1016/0031-9422 (75) $85275-7$

Hernández-Cornejo, R., Koedam, N., Ruiz Luna, A., Troell, M. and Dahdouh-Guebas, F. (2005). Remote sensing and ethnobotanical assessment of the mangrove forest changes in the Navachiste-San Ignacio-Macapule lagoon complex, Sinaloa, Mexico. Ecology and Society, 10(1), 16. https:// doi.org/10.5751/ES-01286-100116

Hou, C.W., Jeng, K.C. and Chen, Y.S. (2010). Enhancement of fermentation process in pu-erh tea by tea-leaf extract. Journal of Food Science, 75(1), H44-H48. https://doi.org/10.1111/j.17503841.2009.01441.X

Kim, H.Y., Yokozawa, T., Nakagawa, T. and Sasaki, S. (2004). Protective effect of $\gamma$-aminobutylic acid against glycerol-induced acute renal failure in rats. Food Chemistry and Toxicology, 42(12), 2009-2014. https://doi.org/10.1016/j.fct.2004.06.021

Ikegaya, K., Takayanagi. H. and Anan, T. (1990). Quantitative analysis of tea constituents (in Japanese). Tea Research Journal, 1990(71), 43-74. https://doi.org/10.5979/cha.1990.43

Kathiresan, K. (1990). Studies on tea from mangrove 
leaves. Environmental Ecology, 13(2), 321-323.

Kinnersley, A.M. and Turano, F.J. (2000). Gamma Aminobutyric Acid (GABA) and Plant Responses to Stress. Critical Reviews in Plant Sciences, 19(6), 479 -509. https://doi.org/10.1080/07352680091139277

Lin, Z., Saito, H., Omori, M., Inomata, T., Kato, M., Sawai, Y., Fukatu, S. and Hakamata, K. (2000). Effect of gabaron tea on the blood pressure and kidney function of rats loaded with saline. Journal of Home Economics of Japan, 51, 265-271. [In Japanese]. https://doi.org/10.11428/jhej1987.51.265

Mori, H., Watanabe, K. and Isono, Y. (2007). Isolation of a lactic acid bacterium, Lactobacillus brevis mh4219, producing high level of $\gamma$-aminobutylic acid (GABA) in tea extract and stress reducing effect of cultured tea beverage containing GABA. Seibutsukogaku kaishi, 85, 521-526. [In Japanese].

Oh, S., Moon, Y. and Oh, C. (2003). $\gamma$-Aminobutyric Acid (GABA) Content of Selected Uncooked Foods. Preventive Nutrition and Food Science, 8(1), 75-78. https://doi.org/10.3746/jfn.2003.8.1.075

Ohtomo, M. (2010). Production and practical use of fermented rice bran contained $\gamma$-aminobutylic acid. Journal of the Brewing Society of Japan, 105(9), 583 -590. [In Japanese]. https://doi.org/10.6013/ jbrewsocjapan.105.583

Okuda, T., Sugishita, T., Murakami, T., Murai, H., Saikusa, T., Horino, T., Onda, A., Kajimoto, O., Takahashi, R. and Takahashi, T. (2000). Effect of the defatted rice germ enriched with GABA for sleeplessness, depression, autonomic disorder by oral administration. Journal of Japanese Society of Food Science and Technology, 47(8), 596-603. [In Japanese].https://doi.org/10.3136/nskkk.47.596

Omori, M., Yano, T., Okamoto, J., Tsushida, T., Murai, T. and Higuchi, M. (1987). Effect of anaerobically treated tea (Gabaron tea) on blood pressure of spontaneously hypertensive rats. Nougei Kagaku, 61, 1449-1451. [In Japanese]. https://doi.org/10.1271/ nogeikagaku1924.61.1449

Park, K. and Oh, S. (2007). Production of yogurt with enhanced levels of gamma-aminobutyric acid and valuable nutrients using lactic acid bacteria and germinated soybean extract. Bioresource Technology, 98(8), 1675-1679. https:// doi.org/10.1016/j.biortech.2006.06.006

Popp, M., Larher, F. and Weigel, P. (1984). Chemical composition of australian mangroves III. Free amino acids, total methylated onium compounds and total nitrogen. Zeitschrift für Pflanzenphysiologie, 114(1), 15-25. https://doi.org/10.1016/S0044-328X(84) 80074-4
Roohinejad, S., Mirhosseini, H., Saari, N., Mustafa, S., Alias, I., Hussin, A.S.M., Hamid, A. and Manap, M.Y. (2009) Evaluation of GABA, crude protein and amino acid composition from different varieties of Malaysian's brown rice. Australian Journal of Crop Science, 3(4), 184-190.

Shelp, B.J., Bown, A.W. and McLean, M.D. (1999). Metabolism and functions of $\gamma$-aminobutyric acid. Trends in Plant Science, 4(11), 446-452. https:// doi.org/10.1016/S1360-1385(99)01486-7

Shirai, N., Suzuki, K. and Ohtsubo, K. (2011). Effects of extruded polished rice, brown rice, and germinated brown rice supplemented with $\mathrm{NaCl}$ on the blood pressure and adipocytokines of spontaneously hypertensive rats (SHR/Izm). The Japanese Society for Food Science and Technology, 58(7), 324-329. [In Japanese]. https://doi.org/10.3136/nskkk.58.324

Spalding, M.D., Kainuma, M. and Collins, L. (2010). World atlas of mangroves. London: Earthscan.

Stark, T., Bareuther, S. and Hofmann, T. (2006). Molecular definition of the taste of roasted cocoa nibs (Theobroma cacao) by means of quantitative studies and sensory experiments. Journal of Agricultural and Food Chemistry, 54, 5530-5539. https://doi.org/10.1021/jf0608726

Wallace, W., Secor, J. and Schrader, L.E. (1984). Rapid accumulation of $\gamma$-aminobutyric acid and alanine in soybean leaves in response to an abrupt transfer to lower temperature, darkness, or mechanical manipulation. Plant Physiology, 75(1), 170-175. https://doi.org/10.1104/pp.75.1.170

Wang, H.F., Tsai, Y.S., Lin, M.L. and Ou, A.S. (2006). Comparison of bioactive components in GABA tea and green tea produced in Taiwan. Food Chemistry, 96(4), 648-653. https://doi.org/10.1016/ j.foodchem.2005.02.046

Yasui, Y., Suzuki, K., Okadome, H., Okunishi, T., Hashimoto, K. and Ohtsubo, K. (2004). Preparation of co-extruded flours using germinated brown rice and barley and its antihypertensive effect: research on development for applications of germinated brown rice Part 1. Journal of the Japanese Society for Food Science and Technology, 51, 592-603. [In Japanese]. https://doi.org/10.3136/nskkk.51.592

Zhao, M., Ma, Y., Wei, Z., Yuan, W., Li, Y., Zhang, C., Xue, X. and Zhou, H. (2010). Determination and Comparison of $\gamma$-Aminobutyric Acid (GABA) Content in Pu-erh and Other Types of Chinese Tea. Journal of Agricultural and Food Chemistry, 59(8), 3641-3648. https://doi.org/10.1021/jf104601v 